\title{
STUDIES ON THE RELATIONSHIP BETWEEN GLUCOSE OXIDATION AND INTERMEDIARY METABOLISM. II. THE ROLE OF GLUCOSE OXIDATION IN LIPOGENESIS IN DIABETIC RAT LIVER ${ }^{1,2}$
}

\author{
By MARVIN D. SIPERSTEIN AND VIOLET M. FAGAN
}

(From the Department of Internal Medicine, The University of Texas Southwestern Medical School, Dallas, Texas)

(Submitted for publication January 13, 1958; accepted February 20, 1958)

In the preceding paper a study was made of the relative importance of the two known glycolytic pathways in controlling lipid synthesis in the liver of normal rats (2). It was concluded that stimulation of fatty acid synthesis observed during accelerated glucose breakdown in normal animals is due primarily to that fraction of the glucose which uses the hexosemonophosphate (HMP) shunt. The Embden-Meyerhof (EM) route of glycolysis, though more important from the standpoint of glucose catabolism, appears to play a relatively minor role in the control of lipogenesis.

The purpose of the investigation to be reported here was to determine whether the depression in fatty acid synthesis which is known to accompany the diabetic state is due to a deficiency of HMP glycolysis or of EM glycolysis.

\section{METHODS}

The treatment of the animals, preparation of homogenates and analytical methods were similar to those used in the preceding paper (2). Diabetes was induced by the intravenous injection of 2 per cent alloxan monohydrate in a dosage of $45 \mathrm{mg}$. per kilogram buffered as described by Klebanoff and Greenbaum (3). The diabetic rats used in these studies had fasting blood sugars of over $250 \mathrm{mg}$. per cent and excreted urine volumes of over $200 \mathrm{ml}$. per day while on the high glucose diet.

\section{RESULTS}

\section{Lipogenesis in homogenates of diabetic liver}

Impaired fatty acid synthesis in diabetic animals, a defect which has been previously shown in both the intact animal using $\mathrm{D}_{2} \mathrm{O}$ (4) and in diabetic liver slices with labeled acetate $(5,6)$, is

\footnotetext{
1 A brief report of these experiments has been previously published (1).

2 These studies were supported by grants from the American Heart Association, the Dallas Heart Association, and the National Heart Institute, United States Public Health Service.
}

also demonstrable in liver homogenates (Table I). Unsupplemented homogenates of normal rat livers have consistently been found to synthesize fatty acids at significant rates (2); however, in liver homogenates from diabetic animals lipogenesis is usually markedly depressed, often to the point that it cannot be detected. The synthetic ability of diabetic homogenates averaged $0.53 \mathrm{~m} \mu \mathrm{M}$ of added acetate-1- $\mathrm{C}^{\mathbf{1 4}}$ incorporated into fatty acids per hour; the corresponding figure for normal livers was $5.1 \mathrm{~m} \mu \mathrm{M}(2)$. A similar observation has been previously made by Shaw and Gurin (7).

\section{Effect of repairing glycolytic pathways on diabetic lipogenesis}

Glucose oxidation over both the EmbdenMeyerhof and the hexosemonophosphate pathways is known to be depressed in diabetes; however, the relationship between these glycolytic defects and the blockage of lipogenesis in diabetes has previously been obscure.

To determine which of these two glycolytic routes is responsible for the lipogenic block in diabetes, glucose oxidation was alternately restored over each of the two glycolytic pathways, as previously described (8), and the effect on lipogenesis was simultaneously measured by observing the incorporation of acetate- $1-\mathrm{C}^{14}$ into fatty acids.

Reinstitution of EM glycolysis in diabetic liver caused a relatively slight increase in fatty acid synthesis of zero to twenty-seven fold, averaging 11.2 (Table I). In contrast, however, a very marked repair of lipogenesis was observed when glucose oxidation via the HMP pathway was restored. This synthesis amounted to from 3 to 730 (average, 91) times that produced by reinstitution of the EM pathway and represents a restoration of diabetic lipogenesis to a level well above that seen in normal control homogenates. 
TABLE I

Influence of glycolytic pathways upon lipid synthesis in diabetic livers*

\begin{tabular}{|c|c|c|c|c|c|c|c|c|c|}
\hline \multirow{2}{*}{$\begin{array}{c}\text { Experi- } \\
\text { ment } \\
\text { number }\end{array}$} & \multirow{2}{*}{$\begin{array}{c}\text { Glycolytic } \\
\text { pathway } \\
\text { stimulated }\end{array}$} & \multicolumn{3}{|c|}{ Acetate-1- $\mathrm{C}^{14}$ converted to: } & \multirow{2}{*}{$\begin{array}{c}\text { Experi- } \\
\text { ment } \\
\text { number }\end{array}$} & \multirow{2}{*}{$\begin{array}{c}\text { Glycolytic } \\
\text { pathway } \\
\text { stimulated }\end{array}$} & \multicolumn{3}{|c|}{ Acetate-1-C ${ }^{14}$ converted to: } \\
\hline & & $\begin{array}{c}\text { Fatty } \\
\text { acid }\end{array}$ & Cholesterol & $\mathrm{CO}_{2}$ & & & $\begin{array}{l}\text { Fatty } \\
\text { acid }\end{array}$ & Cholesterol & $\mathrm{CO}_{2}$ \\
\hline 1 & $\begin{array}{l}\text { Neither } \\
\text { HMP } \\
\text { EM } \\
\text { HMP+EM }\end{array}$ & $\begin{array}{l}m \mu M \\
<0.1 \\
73 \\
<0.1 \\
302\end{array}$ & $\begin{array}{c}m \mu M \times 10^{-2} \\
<3 \\
302 \\
<3 \\
309\end{array}$ & $\begin{array}{r}m \mu M \\
3 \\
84 \\
4 \\
68\end{array}$ & 7 & $\begin{array}{l}\text { Neither } \\
\text { HMP } \\
\text { EM } \\
\text { HMP+EM }\end{array}$ & $\begin{array}{c}m \mu M \\
0.6 \\
130 \\
15 \\
159\end{array}$ & $\begin{array}{c}m \mu M \times 10^{-2} \\
<3 \\
3,052 \\
<3 \\
2,577\end{array}$ & $\begin{array}{r}m \mu M \\
25 \\
168 \\
95 \\
138\end{array}$ \\
\hline 2 & $\begin{array}{l}\text { Neither } \\
\text { HMP } \\
\text { EM } \\
\text { HMP+EM }\end{array}$ & $\begin{array}{c}<0.3 \\
28 \\
1.2 \\
263\end{array}$ & $\begin{array}{l}<6 \\
62 \\
<6 \\
52\end{array}$ & $\begin{array}{r}4 \\
111 \\
6 \\
85\end{array}$ & 8 & $\begin{array}{l}\text { Neither } \\
\text { HMP } \\
\text { EM } \\
\text { HMP+EM }\end{array}$ & $\begin{array}{l}0.3 \\
34 \\
8 \\
26\end{array}$ & $\begin{array}{r}5 \\
494 \\
205\end{array}$ & $\begin{array}{r}9 \\
76 \\
63 \\
67\end{array}$ \\
\hline 3 & $\begin{array}{l}\text { Neither } \\
\text { HMP } \\
\text { EM } \\
\text { HMP+EM }\end{array}$ & $\begin{array}{c}<0.3 \\
30 \\
0.6 \\
88\end{array}$ & $\begin{array}{r}<6 \\
754 \\
<6 \\
1,066\end{array}$ & $\begin{array}{r}3 \\
76 \\
3 \\
96\end{array}$ & 9 & $\begin{array}{l}\text { Neither } \\
\text { HMP } \\
\text { EM } \\
\text { HMP+EM }\end{array}$ & $\begin{array}{l}0.3 \\
45 \\
4 \\
58\end{array}$ & $\begin{array}{r}<3 \\
237 \\
<3 \\
166\end{array}$ & $\begin{array}{r}8 \\
49 \\
36 \\
54\end{array}$ \\
\hline 4 & $\begin{array}{l}\text { Neither } \\
\text { HMP } \\
\text { EM } \\
\text { HMP+EM }\end{array}$ & $\begin{array}{l}<0.3 \\
38 \\
<0.3 \\
78\end{array}$ & $\begin{array}{l}<5 \\
<5 \\
<5 \\
<5\end{array}$ & $\begin{array}{r}5 \\
91 \\
2 \\
67\end{array}$ & 10 & $\begin{array}{l}\text { Neither } \\
\text { HMP } \\
\text { EM } \\
\text { HMP+EM }\end{array}$ & $\begin{array}{l}0.7 \\
85 \\
14 \\
99\end{array}$ & $\begin{array}{r}<3 \\
49 \\
<3 \\
-\quad 16\end{array}$ & $\begin{array}{l}10 \\
38 \\
27 \\
36\end{array}$ \\
\hline 5 & $\begin{array}{l}\text { Neither } \\
\text { HMP } \\
\text { EM } \\
\text { HMP+EM }\end{array}$ & $\begin{array}{l}0.8 \\
35 \\
8 \\
74\end{array}$ & $\begin{array}{r}10 \\
2,100 \\
10 \\
936\end{array}$ & $\begin{array}{r}6 \\
75 \\
63 \\
82\end{array}$ & 11 & $\begin{array}{l}\text { Neither } \\
\text { HMP } \\
\text { EM } \\
\text { HMP +EM }\end{array}$ & $\begin{array}{c}0.4 \\
126 \\
5 \\
55\end{array}$ & $\begin{array}{r}<3 \\
234 \\
<3 \\
26\end{array}$ & $\begin{array}{r}9 \\
64 \\
40 \\
28\end{array}$ \\
\hline 6 & $\begin{array}{l}\text { Neither } \\
\text { HMP } \\
\text { EM } \\
\text { HMP+EM }\end{array}$ & $\begin{array}{c}0.3 \\
12 \\
4 \\
21\end{array}$ & $\begin{array}{r}<5 \\
286 \\
<5 \\
52\end{array}$ & $\begin{array}{r}6 \\
51 \\
53 \\
45\end{array}$ & 12 & $\begin{array}{l}\text { Neither } \\
\text { HMP } \\
\text { EM } \\
\text { HMP+EM }\end{array}$ & $\begin{array}{r}2 \\
37 \\
12 \\
40\end{array}$ & $\begin{array}{r}<3 \\
10 \\
<3 \\
3\end{array}$ & $\begin{array}{l}43 \\
47 \\
73 \\
52\end{array}$ \\
\hline
\end{tabular}

* Cofactor and substrate concentration: glucose-6-phosphate, $18 \times 10^{-3} \mathrm{M} ; \mathrm{TPN}, 0.7 \times 10^{-3} \mathrm{M} ; \mathrm{DPN}, 0.7 \times 10^{-3}$ $\mathrm{M}$; potassium acetate, $2 \times 10^{-3} \mathrm{M}$. Total volume in Experiments 1 through 3 was $2.5 \mathrm{ml}$.; in Experiments 4 through 12 the volume was $1.4 \mathrm{ml}$.

In fact, reinstitution of HMP glycolysis stimulated the rates of fatty acid synthesis in the diabetic homogenates to the extent (i.e., an average of 189 times the control levels) that, though these values averaged less, they fell within the range of those for HMP-stimulated lipogenesis in normal homogenates (2). As in the case of normal liver the simultaneous stimulation of both pathways of glycolysis usually caused a maximal increase in lipogenesis.

\section{The deficient cofactor in diabetic lipogenesis}

Since reduced triphosphopyridine nucleotide (TPNH) was found to mediate the stimulatory effects of HMP glycolysis on lipid synthesis in normal liver, it seemed possible that a deficiency of this cofactor might be responsible for the lipogenic lesion of diabetes. An attempt was therefore made to repair this lesion by means of an alternate TPNH generating system, isocitrate and triphosphopyridine nucleotide (TPN). The data in Table II demonstrate that this source of TPNH will correct the defect in diabetic lipogenesis at least as well as will the HMP shunt. The addition to the system of either TPN or isocitrate alone, while increasing fatty acid synthesis, had much less effect than did the complete generating system.

\section{Cholesterol synthesis}

Cholesterol synthesis in diabetic liver was found to be considerably stimulated by HMP glycolysis (Table I), and in the case of lipogenesis, the alternate TPNH generating system was successfully substituted for HMP oxidation (Table II). TPN without additional substrate, however, caused a very marked stimulation of cholesterol synthesis and it is likely, as was discussed in the previous report (2), that this reflects the require- 
TABLE II

Influence of reduced triphosphopyridine nucleotide (TPNH) generating systems upon fatty acid and cholesterol synthesis in diabetic liver

\begin{tabular}{|c|c|c|c|}
\hline \multirow[b]{2}{*}{$\begin{array}{l}\text { Experi- } \\
\text { ment }\end{array}$} & \multirow[b]{2}{*}{ Cofactor and/or substrate } & \multicolumn{2}{|c|}{$\begin{array}{l}\text { Acetate- } C^{14} \text { con- } \\
\text { verted to: }\end{array}$} \\
\hline & & $\begin{array}{l}\text { Fatty } \\
\text { acids }\end{array}$ & Cholesterol \\
\hline 1 & $\begin{array}{l}\text { Glucose-6-phosphate } \\
\text { Potassium isocitrate } \\
\text { TPN + glucose-6-phosphate } \\
\text { TPN + potassium isocitrate } \\
\text { TPN }\end{array}$ & $\begin{array}{r}m \mu M \\
0.5 \\
7.3 \\
40.6 \\
71.2 \\
10.9\end{array}$ & $\begin{array}{c}m \mu M \times 10^{-} \\
<5 \\
<5 \\
99 \\
36 \\
73\end{array}$ \\
\hline 2 & $\begin{array}{l}\text { Glucose-6-phosphate } \\
\text { Potassium isocitrate } \\
\text { TPN + glucose-6-phosphate } \\
\text { TPN + potassium isocitrate } \\
\text { TPN }\end{array}$ & $\begin{array}{r}0.1 \\
7.2 \\
26.1 \\
99.5 \\
0.8\end{array}$ & $\begin{array}{l}<2 \\
<2 \\
330 \\
140 \\
340\end{array}$ \\
\hline
\end{tabular}

Concentration of additions :

Experiment 1. TPN, $0.8 \times 10^{-3} \mathrm{M}$; glucose-6-phosphate, $21 \times 10^{-3} \mathrm{M}$; potassium isocitrate, $21 \times 10^{-3}$ $M$ in a totål volume of $2.7 \mathrm{ml}$.

Experiment 2. TPN, $0.7 \times 10^{-3} \mathrm{M}$; glucose-6-phosphate, $18 \times 10^{-3} \mathrm{M}$; potassium isocitrate, $2 \times 10^{-3}$ $\mathrm{M}$ in a total volume of $1.4 \mathrm{ml}$.

ment for a lesser concentration of $\mathrm{TPNH}$ for cholesterolgenesis than for lipogenesis.

\section{$\mathrm{C}^{14} \mathrm{O}_{2}$ production}

In all but one case (Experiment 12, Table I), supplementation with TPN caused a marked in-

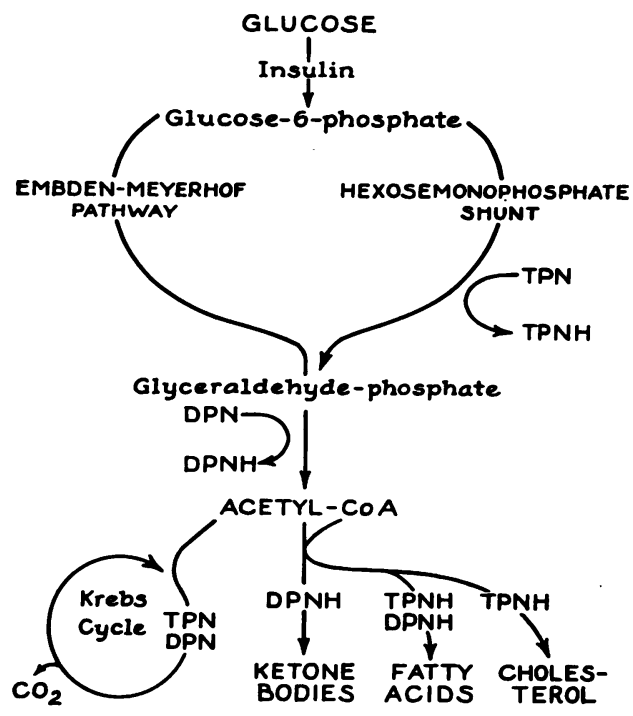

Fig. 1. A Summary of Glycolytic Pathways and Their Articulation, Especially via Pyridine NuCleotides, with Several Other INTRacellular FuncTIONS crease in the production of $\mathrm{C}^{14} \mathrm{O}_{2}$ from acetate1-C ${ }^{14}$. Diphosphopyridine nucleotide (DPN) usually caused a significant stimulation, though of somewhat smaller magnitude than was seen with TPN. The response to the addition of both cofactors was not significantly greater than that usually produced by either TPN or by DPN alone.

\section{DISCUSSION}

The nature of the lipogenic defect in diabetes has been thoroughly discussed in recent reviews by Chaikoff (9) and by Stadie (10). It has been clear for some years that this lesion is in some manner due to a lack of insulin action since, as was shown by Chernick and Chaikoff (11), the administration of this hormone to diabetic animals will promptly restore lipogenesis to normal or above-normal levels. These authors have concluded that the inability of the diabetic animal to convert glucose into fatty acids cannot be explained solely on the basis of a single metabolic block, presumably involving the phosphorylation of glucose, and they have suggested the existence of a second block, located on the pathway of synthesis of fatty acids from a two-carbon compound (acetylcoenzyme A). Figure 1 summarizes this and the other relationships between glycolysis and the metabolic processes, to be discussed below.

Baker, Chaikoff, and Schusdek (12) subsequently demonstrated that fatty acid synthesis in the diabetic could be restored to normal simply by prefeeding with fructose, a sugar which does not require insulin for its metabolism. The diabetic defect in lipogenesis is therefore not due to a lack of a direct insulin stimulation of lipogenesis but is in fact secondary to the decrease in glycolysis. This conclusion was further supported by the finding of Shaw and Gurin that lipogenesis in diabetic homogenates could be in part corrected by the addition of a number of those glycolytic intermediates involved beyond the insulin sensitive step in glucose metabolism (7). It seemed likely, therefore, that some factor normally produced during the process of glycolysis serves to maintain normal fatty acid synthesis and that this factor is then lacking in the diabetic state.

The first object of the present study was to determine whether a deficiency of one of the two pathways of glycolysis, i.e., the Embden-Meyerhof 


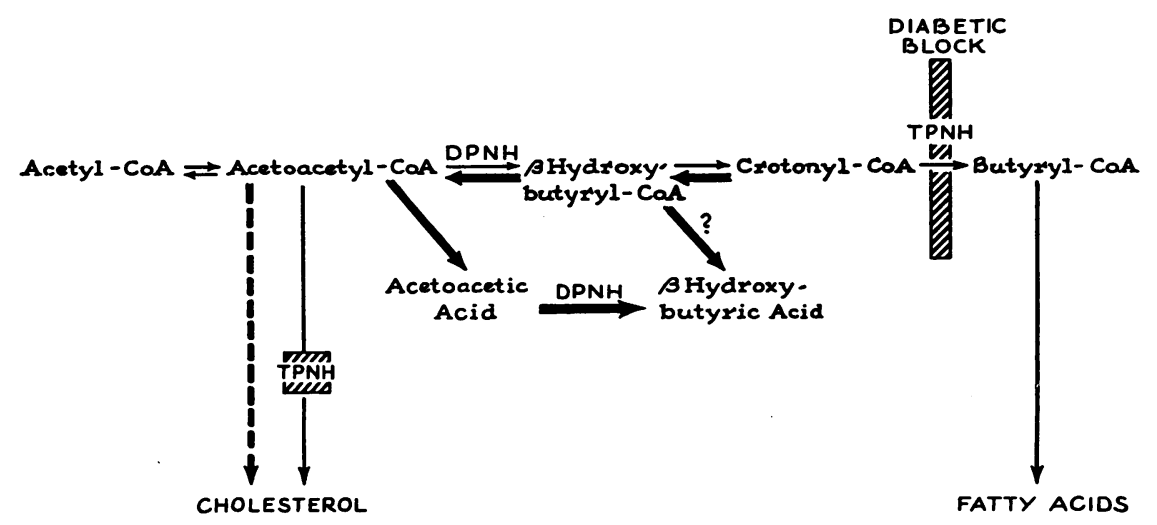

Fig. 2. An Explanation, Based on a TPNH Deficiency, of Some of the Metabolic Lesions of Diabetes

route or the hexosemonophosphate shunt, is responsible for the lipogenic lesion in diabetes.

Despite the fact that the EM pathway is normally the quantitatively more important pathway, the results given in Table I indicate that reinstitution of EM glycolysis does not significantly stimulate lipogenesis in diabetic livers. On the other hand, restoration of HMP glycolysis caused a very significant increase in lipogenesis, the HMP route being approximately ninetyfold more effective than the EM pathway.

It is concluded from these experiments, therefore, that the block in lipogenesis of diabetic liver can be repaired simply by reinstitution of HMP glycolysis and it follows that this lesion in fatty acid synthesis may be ascribed in the diabetic primarily to a lack of glucose oxidation via the hexosemonophosphate pathway. The cofactors generated by EM glycolysis, though doubtless necessary for lipogenesis, would appear from our data to be supplied in adequate amounts despite the marked reduction in this glycolytic system in the diabetic state, or else, as will be discussed below, such factors are amply provided to the cell by reactions other than glycolysis. On the other hand, since it is clear from the results of this study that a deficiency in the HMP shunt does markedly inhibit lipogenesis, the lack of a factor normally supplied by this reaction is presumably chiefly responsible for the defective lipogenesis of diabetes.

The nature of this cofactor was suggested by the demonstration that HMP glycolysis is not unique in its ability to repair the lipogenic lesion of diabetes. Isocitrate and TPN, another system which, like HMP glycolysis, produces TPNH, is also capable of restoring lipogenesis in diabetic liver. It is likely, therefore, that the inability of the diabetic to synthesize fatty acids is due specifically to a deficiency of the coenzyme, TPNH.

The site of action of TPNH in the process of fatty acid synthesis, as has been shown by Langdon, is probably at the conversion of crotonyl-CoA to butyryl-CoA (13). Our demonstration that TPNH is the cofactor whose deficiency appears to be primarily responsible for the block in diabetic lipogenesis therefore locates the site of the diabetic lesion at this reductive step in the pathway of fatty acid synthesis (Figure 2). The recent finding of Shaw, Dituri, and Gurin (14) that butyryl-CoA will stimulate fatty acid synthesis in diabetic liver indicated that this lesion is located at some point prior to the synthesis of butyryl-CoA and so is consistent with the site of the block suggested here. However, for reasons that are not apparent these investigators were unable to show an effect of TPNH on lipogenesis.

The location of the major lipogenic defect in diabetes at the point of conversion of crotonylCoA to butyryl-CoA is also consistent with a number of the clinical observations of diabetic ketosis and in addition offers an explanation for the nature of the organic acids which appear in this derangement. The two four-carbon ketone bodies which accumulate in uncontrolled diabetes are acetoacetic acid and $\beta$-hydroxybutyric acid. These are two of the acids whose activated derivatives are required in fatty acid synthesis before the block at the site of TPNH action (Figure 2). We would suggest 
that these two activated acids increase in concentration in diabetes because a lack of TPNH prevents them from being converted to fatty acids, and as illustrated by the thick solid arrows in Figure 2, they then become dammed behind this metabolic block. The hydrolysis of the coenzyme A from each of these compounds could then cause an accumulation of free acetoacetic and $\beta$-hydroxybutyric acids. On the other hand, increased quantities of $\beta$-hydroxybutyric acid can be formed by reduction of the large amounts of free acetoacetic acid (Figure 2), and in fact there is evidence that this is the major route of its production (15). In either case, as a result of the TPNH block, the two acids actually observed in excess in diabetic ketosis would be expected to accumulate. Crotonyl-CoA, the compound occurring just prior to the TPNH block, might not increase in concentration in diabetes since the equilibrium between it and $\beta$-hydroxybutyryl-CoA is known to favor the latter (16), and this fact may account for the probable absence of pathological quantities of free crotonic acid in diabetic ketosis. The conclusions of our in vitro studies can therefore provide an explanation of the nature of diabetic ketosis which is quite consistent with the findings in the clinical state. $^{3}$

In this regard, it should be emphasized that the relative ineffectuality of Embden-Meyerhof glycolysis in correcting the diabetic lesion in our experiments is also consistent with the findings in clinical diabetes ketosis. The diabetic retains the ability to synthesize large quantities of $\beta$-hydroxybutyric acid, and this is often the predominant ketone body present in diabetic ketosis. Since formation of $\beta$-hydroxybutyric acid requires the action of reduced diphosphopyridine nucleotide (DPNH) (Figure 2), it is unlikely that a lack of this coenzyme, and hence a depression of the EmbdenMeyerhof pathway, are responsible for the metabolic lesions of the intact diabetic animal. It should be noted that during the oxidation of fatty acids one molecule of DPNH is produced for each

${ }^{3}$ A liver enzyme system has recently been purified (17) which is capable of forming fatty acids using TPNH as the sole reducing coenzyme (18). In this system a deficiency of TPNH might then be manifest as a block in the conversion of acetoacetyl-CoA to $\beta$-hydroxybutyrylCoA. Acetoacetic and $\beta$-hydroxybutyric acid would then accumulate as described above. two carbons removed from the fatty acid molecule, while on the other hand no TPNH is believed to result from these reactions (19). It is possible, therefore, that DPNH but not TPNH may be supplied to the cell in adequate quantities by reactions other than glycolysis.

The observation that repair of diabetic lipogenesis will result from restoring the function of the hexosemonophosphate shunt is fully consistent with the conclusion that the "second" block in diabetic metabolism is not due to a lack of insulin per se. The location and mechanism of this lesion, as suggested here, indicate that both this defect in lipogenesis and the resulting ketosis of diabetes are secondary to the depressed glucose oxidation. It follows therefore that these lesions can probably all be explained on the basis of a single action of insulin at the site of the initial phosphorylation of glucose.

Whether a deficiency of insulin causes a greater depression of HMP glycolysis than of EM glycolysis, as has been suggested by recent studies (2022 ), remains to be finally decided (23). A selective depression of the HMP pathway in diabetes due to a decrease either of TPN or of HMP enzymes $(22,24)$ is, however, consistent with the data and concept presented here.

The synthesis of cholesterol was also very greatly increased by reinstitution of HMP glycolysis in the diabetic liver homogenate and a block in this pathway is therefore shown in the scheme of diabetic metabolism, illustrated in Figure 2. The abnormally elevated rates of cholesterol synthesis which have been noted in diabetic liver slices (25) were not observed in the present studies. Our data suggest, however, that the synthesis of cholesterol may require smaller concentrations of TPNH than does fatty acid synthesis (2) (Table II). It is possible, therefore, that cholesterol synthesis is less affected by a deficiency of TPNH. The increased cholesterolgenesis seen in diabetic liver might then be due to the stimulatory effect of acetoacetyl-CoA accumulation; this possibility is indicated by the thick dotted arrow in Figure 2.

Finally, in contrast to the case in normal liver (2), a stimulation of the Krebs cycle was regularly obtained by the addition of pyridine nucleotides to diabetic liver. This observation is consistent with the lower levels of pyridine nucleotides found in diabetic liver by Glock and McLean (24) and sug- 
gests that availability of pyridine nucleotides may become a controlling factor in the operation of the Krebs cycle in the diabetic cell. Further studies of this phenomenon are in progress.

\section{SUM MARY}

1. The cause of the lipogenic defect which accompanies diabetes has been investigated in cellfree liver preparations from alloxan diabetic rats.

2. It is concluded that this metabolic lesion is due primarily to a deficiency of glucose oxidation via the hexosemonophosphate pathway of glycolysis; the lack of glycolysis via the EmbdenMeyerhof route, which also accompanies the diabetic state, apparently plays a minor role in depressing lipogenesis.

3. Evidence is presented which indicates that a deficiency of the reduced triphosphopyridine nucleotide (TPNH), normally produced by the hexosemonophosphate route, is the specific cause of the lipogenic defect in diabetes.

4. A concept of the nature of diabetic ketosis is presented based on a block at the site of action of TPNH in fatty acid synthesis.

\section{REFERENCES}

1. Siperstein, M. D., and Fagan, V. M. Role of glycolysis in fatty acid and cholesterol synthesis in normal and diabetic rats. Science 1957, 126, 1012.

2. Siperstein, M. D., and Fagan, V. M. Studies on the relationship between glucose oxidation and intermediary metabolism. I. The influence of glycolysis on the synthesis of cholesterol and fatty acids in normal liver. J. clin. Invest. 1958, 37, 1185.

3. Klebanoff, S. J., and Greenbaum, A. L. The effect of $\mathrm{pH}$ on the diabetogenic action of alloxan. J. Endocr. 1954, 11, 314.

4. Stetten, D., Jr., and Boxer, G. E. Studies in carbohydrate metabolism. III. Metabolic defects in alloxan diabetes. J. biol. Chem. 1944, 156, 271.

5. Brady, R. O., and Gurin, S. Biosynthesis of labeled fatty acids and cholesterol in experimental diabetes. J. biol. Chem. 1950, 187, 589.

6. Chernick, S. S., and Chaikoff, I. L. Two blocks in carbohydrate utilization in the liver of the diabetic rat. J. biol. Chem. 1951, 188, 389.

7. Shaw, W., and Gurin, S. Relationship of glycolysis to lipogenesis in aqueous extracts of liver. Arch. Biochem. 1953, 47, 220.

8. Siperstein, M. D., and Fagan, V. M. The influence of pyridine nucleotides on the pathways of glucose oxidation. Submitted for publication.
9. Chaikoff, I. L. Metabolic blocks in carbohydrate metabolism in diabetes. The Harvey Lectures, 1951-1952. New York, Academic Press Inc., 1953, vol. 47, p. 99.

10. Stadie, W. C. Current concepts of the action of insulin. Physiol. Rev. 1954, 34, 52.

11. Chernick, S. S., and Chaikoff, I. L. Insulin and hepatic utilization of glucose for lipogenesis. $\mathrm{J}$. biol. Chem. 1950, 186, 535.

12. Baker, N., Chaikoff, I. L., and Schusdek, A. Effect of fructose on lipogenesis from lactate and acetate in diabetic liver. J. biol. Chem. 1952, 194, 435.

13. Langdon, R. G. The requirement of triphosphopyridine nucleotide in fatty acid synthesis. J. Amer. chem. Soc. 1955, 77, 5190.

14. Shaw, W. N., Dituri, F., and Gurin, S. Lipogenesis in particle-free extracts of rat liver. II. Experimental diabetes. J. biol. Chem. 1957, 226, 417.

15. Lehninger, A. L., and Greville, G. D. The enzymic oxidation of d- and 1- $\beta$-hydroxybutyrate. Biochim. Biophys. Acta 1953, 12, 188.

16. Stern, J. R., and del Campillo, A. Enzymes of fatty acid metabolism. II. Properties of crystalline crotonase. J. biol. Chem. 1956, 218, 985.

17. Wakil, S. J., Porter, J. W., and Gibson, D. M. Studies on the mechanism of fatty acid synthesis. I. Preparation and purification of an enzyme system for reconstruction of fatty acid synthesis. Biochim. Biophys. Acta 1957, 24, 453.

18. Titchener, E. B., Gibson, D. M., and Wakil, S. J. Requirements for fatty acid biosynthesis. Fed. Proc. 1958, 17, 322.

19. Green, D. E. Oxidation and synthesis of fatty acids in soluble enzyme systems of animal tissues. Clin. Chem. 1955, 1, 53.

20. Bloom, B. Fraction of glucose catabolized via the Embden-Meyerhof pathway: Alloxan-diabetic and fasted rats. J. biol. Chem. 1955, 215, 467.

21. Felts, J. M., Doell, R. G., and Chaikoff, I. L. The effect of insulin on the pathways of conversion of glucose to fatty acids in the liver. J. biol. Chem. 1956, 219, 473.

22. Glock, G. E., and McLean, P. A preliminary investigation of the hormonal control of the hexose monophosphate oxidative pathway. Biochem. J. 1955, 61, 390.

23. Ashmore, J., Cahill, G. F., Jr., Hastings, A. B., and Zottu, S. Studies on carbohydrate metabolism in rat liver slices. VIII. Effect of ions and hormones on pathways of glucose-6-phosphate metabolism. J. biol. Chem. 1957, 224, 225.

24. Glock, G. E., and McLean, P. Effects of hormones on levels of oxidized and reduced diphosphopyridine nucleotide and triphosphopyridine nucleotide in liver and diaphragm. Biochem. J. 1955, 61, 397.

25. Hotta, S., and Chaikoff, I. L. Cholesterol synthesis from acetate in the diabetic liver. J. biol. Chem. 1952, 198, 895. 